\title{
En ung kvinne som drakk streptestreagens
}

\author{
En kvinne i 20-årene ble brakt til legevakten grunnet psykotiske sym- \\ ptomer, og man vurderte det slik at hun måtte tvangsinnlegges. Mens \\ hun var på legevakten drakk hun to små flasker med reagenser som \\ hun fant $\mathrm{i}$ et streptestsett. Hun ble deretter somnolent og fikk nedsatt \\ oksygenmetning. Veiledning fra Giftinformasjonen var nødvendig for \\ rask avklaring og riktig behandling.
}

En kvinne i 20-årene kom til legevakten med ambulanse etter å ha hoppet $i$ sjøen. Klærne var våte, hun var forkommen og hadde påfallende atferd med symptomer som ga mistanke om psykose. Hun anga å ha hoppet $i$ sjøen som en impulshandling, og benektet at det lå selvmordstanker bak. Kvinnen fortalte at hun bestemte seg for å hoppe sekunder forkant. Hun ga uttrykk for å være glad for å bli hentet opp fra sjøen og for å få hjelp. Det ble konferert med psykiater, og det fremkom at hun tidligere hadde gått ukentlig til psykolog. Hun brukte ingen medikamenter. Dagen før hadde hun drukket alkohol og røyket marihuana, men nærmere kartlegging av rusbruk ble ikke gjort på dette tidspunktet.

Ved undersøkelse hadde hun regelmessig puls på 79 slag per minutt, øretemperatur $36,4^{\circ} \mathrm{C}$, pulsoksymetrisk oksygenmetning $100 \%$ på romluft og blodsukker på 6,2 $\mathrm{mmol} / \mathrm{l}(4,0-8,0 \mathrm{mmol} / \mathrm{l})$. Huden var tørr og varm, og hun pustet ubesværet. Pupillene var sidelike og normalt store med normal lysreaksjon. Hun hadde ingen ytre tegn til hodeskade eller skade annet sted, normal kraft i armer og bein og symmetriske ekstremitetsbevegelser.

På mistanke om rusutløst psykose ble det etter klinisk undersøkelse og psykiatrisk vurdering besluttet at hun skulle legges inn i psykiatrisk avdeling til tvungen observasjon. Det var ventetid på ambulanse, og $i$ mellomtiden ble hun observert hyppig av både sykepleier og lege. I ventetiden var hun motorisk urolig og demonterte medisinsk utstyr på undersøkelsesrommet.

Pasienten ble vurdert som psykotisk, men ikke suicidal. Hun ble imidlertid vurdert til å kunne være til fare for seg selv på grunn av den dramatiske impulshandlingen og vedvarende motorisk uro, og innleggelse i psykiatrisk avdeling ble vurdert som påkrevd. Forsøk på å få pasientens samtykke til frivillig innleggelse lyktes ikke, og man besluttet derfor å legge pasienten inn til tvungen observasjon (§ 3-2 i lov om psykisk helsevern).
Rett før avreise fra legevakten fant personalet tomme streptestreagensflasker på gulvet på undersøkelsesrommet, og pasienten bekreftet at hun hadde drukket innholdet i flaskene. Det var ikke kjent hvor mye av innholdet som var igjen i flaskene på forhånd, slik at det var usikkert hvor mye hun hadde inntatt.

Streptestreagensene, som brukes til å påvise streptokokkinfeksjon i halsen (fig 1), var plassert på en tralle på undersøkelsesrommet, som en del av standardutstyret på de fleste undersøkelsesrom ved legevakten. Pasienten hadde drukket flasker inneholdende $2 \mathrm{M}$ natriumnitritt, og 0,2 $\mathrm{M}$ eddiksyre.

Pasienten ble hyppig tilsett, men var ikke under konstant overvåking. Det er vanskelig å forutse hvilke pasienter som kommer til å gjøre skade på seg selv. Personell er en knapp ressurs, og på legevakt er det ofte mange samtidige behov. Selv om denne pasienten skulle tvangsinnlegges, ble hyppige tilsyn vurdert som tilstrekkelig grad av overvåking, noe det dessverre viste seg ikke å være.

Giftinformasjonen ble umiddelbart kontaktet, og etter informasjon om reagensenes toksiske virkning ble det besluttet at pasienten skulle innlegges i lokalsykehus for observasjon. Ved avreise fra legevakten var hun våken, respiratorisk og sirkulatorisk stabil.

Transporttiden til sykehuset var kort, og hun ankom akuttmottaket om lag 45 minutter etter inntak av reagensene. Ved ankomst forelå ikke opplysningene fra legevakten, og det var dermed ikke kjent for mottakende lege hva slags reagens pasienten hadde drukket. Ved klinisk undersøkelse var Glasgow Coma Scale (GCS)-skår 15, og hun samarbeidet greit. Hun hadde leppecyanose, men for øvrig hadde huden normal farge. Ekstremitetene var kalde perifert og uten tegn til cyanotiske forandringer. Det ble bemerket lett ødem i ansiktet. Blodtrykket var 112/56, hun hadde regelmessig puls på 90/min, respirasjonsfrekvens 18/min og $\mathrm{SaO}_{2}$ var $82 \%$ uten oksygentilskudd. Klinisk

\author{
Vivian M. Dalaker \\ viviandalaker@hotmail.com \\ Allmennlegevakten \\ Oslo kommune, Helseetaten \\ Odd Martin Vallersnes \\ Allmennlegevakten \\ Oslo kommune, Helseetaten \\ og \\ Avdeling for allmennmedisin \\ Universitetet i Oslo

\section{Linn Elisabeth Fosshaug} \\ Medisinsk avdeling \\ Diakonhjemmet sykehus \\ og
}

Institutt for indremedisinsk forskning

Oslo universitetssykehus, Rikshospitalet

Kirsti S. Andersson

Akuttmedisinsk avdeling

Oslo universitetssykehus

og

Medisinsk klinikk

Oslo universitetssykehus, Ullevål

\section{Knut Erik Hovda}

Nasjonal behandlingstjeneste for CBRNe-medisin og

Akuttmedisinsk avdeling

Oslo universitetssykehus, Ullevål

Engelsk oversettelse på www.tidsskriftet.no 
status, EKG og orienterende blodprøver var for øvrig normale. Arteriell blodgass viste $\mathrm{pO}_{2} 11,1 \mathrm{kPa}(10,0-14,0 \mathrm{kPa}), \mathrm{pCO}_{2} 4,6 \mathrm{kPa}$ (4,7-6,0 kPa) og bikarbonat $25 \mathrm{mmol} / \mathrm{l}$ (22-26 mmol/l). På grunn av uforklart cyanose, motorisk uro, tegn på psykose og et forgiftningsagens som der og da var ukjent, ble pasienten overført til intensivavdelingen for videre observasjon. Før overføringen fikk hun olanzapin $10 \mathrm{mg}$ per os. Olanzapin ble valgt som beroligende middel på grunn av sin antipsykotiske effekt.

$P$ å intensivavdelingen tok sykepleier ny arteriell blodgass, og hun bemerket en mørk og brunlig farge på blodet før analyse (fig 2). Pasienten lå da med 4 liter oksygen på nesekateter, $\mathrm{pO}_{2}$ var $22,4 \mathrm{kPa}, \mathrm{PCO}_{2} 5,4 \mathrm{kPa}$, bikarbonat $27,5 \mathrm{mmol} / \mathrm{l}$, laktat $0,8 \mathrm{mmol} / \mathrm{l}$ (0,5-1,4 mmol/l), og elektrolytter var normale (tab 1). Det var diskrepans mellom perifer metningsmåling $\left(\mathrm{SaO}_{2}\right)$ på 79-83\% og arteriell $\mathrm{pO}_{2}$ på $22,4 \mathrm{kPa}$. Ved nytt legetilsyn en times tid senere var opplysninger fra legevakten innhentet, og methemoglobinemi ble mistenkt på grunn av «sjokoladefarget» blod og inntak av nitritt. Nivået av methemoglobin var $22 \%$ (referanseområde $<1,0 \%$ ), og pasienten var tiltakende somnolent. Giftinformasjonen ble kontaktet på nytt for avklaring av behandlingsindikasjon og overvåkningsnivå, og etter anbefaling fra medisinsk bakvakt der, ble det avtalt overføring til regionsykehus for vurdering av antidotbehandling.

Forgiftning med nitritt er sjelden, men kan føre til danning av methemoglobinemi med påfølgende cyanose og svikt i oksygentransporten. $\mathrm{SaO}_{2}$ vil oftest være lav, mens blodgassanalyse viser tilnærmet normal $\mathrm{pO}_{2}$, samtidig som blodet har en brunblå farge («sjokoladecyanose») som vises tydeligst på lepper og slimhinner $(1,2)$. Ved noen målinger hos vår pasient var $\mathrm{pO}_{2}$-nivået over referanseverdien, men det skyldtes $\mathrm{O}_{2}$-tilførselen.

Ved ankomst regionsykehuset var hun somnolent, hadde regelmessig puls på 64, blodtrykk 99/58 $\mathrm{mm} \mathrm{Hg}$, respirasjonsfrekvens på 18 og $\mathrm{SaO}_{2}$ på $94 \%$ med 15 liter $\mathrm{O}_{2}$ på maske. Pasienten ble innlagt $i$ medisinsk intensivavdeling. Blodgass viste nå $\mathrm{pO}_{2} 63,8, \mathrm{SaO}_{2}$ $99,8 \%$ og methemoglobin $17 \%$. Hb var 12,0 $\mathrm{g} / \mathrm{dl}(11,7-15,3 \mathrm{~g} / \mathrm{dl})$, elektrolytter normale og glukose 9,3 (tab 1). Blodprøver for øvrig viste hvite blodceller $6,0(3,5-10,0)$, nøytrofile granulocytter 2,5 (1,5-7,3), normalt kreatininnivå, normale leverfunksjonsprøver og negativt CRP-nivå. EKG var normalt.

Siden methemoglobinnivået ikke var høyere enn $17 \%$, ble det i første omgang ikke igangsatt behandling med antidot. Anbefalt grense for behandling er 25-30\% $(1,2)$. Pasienten

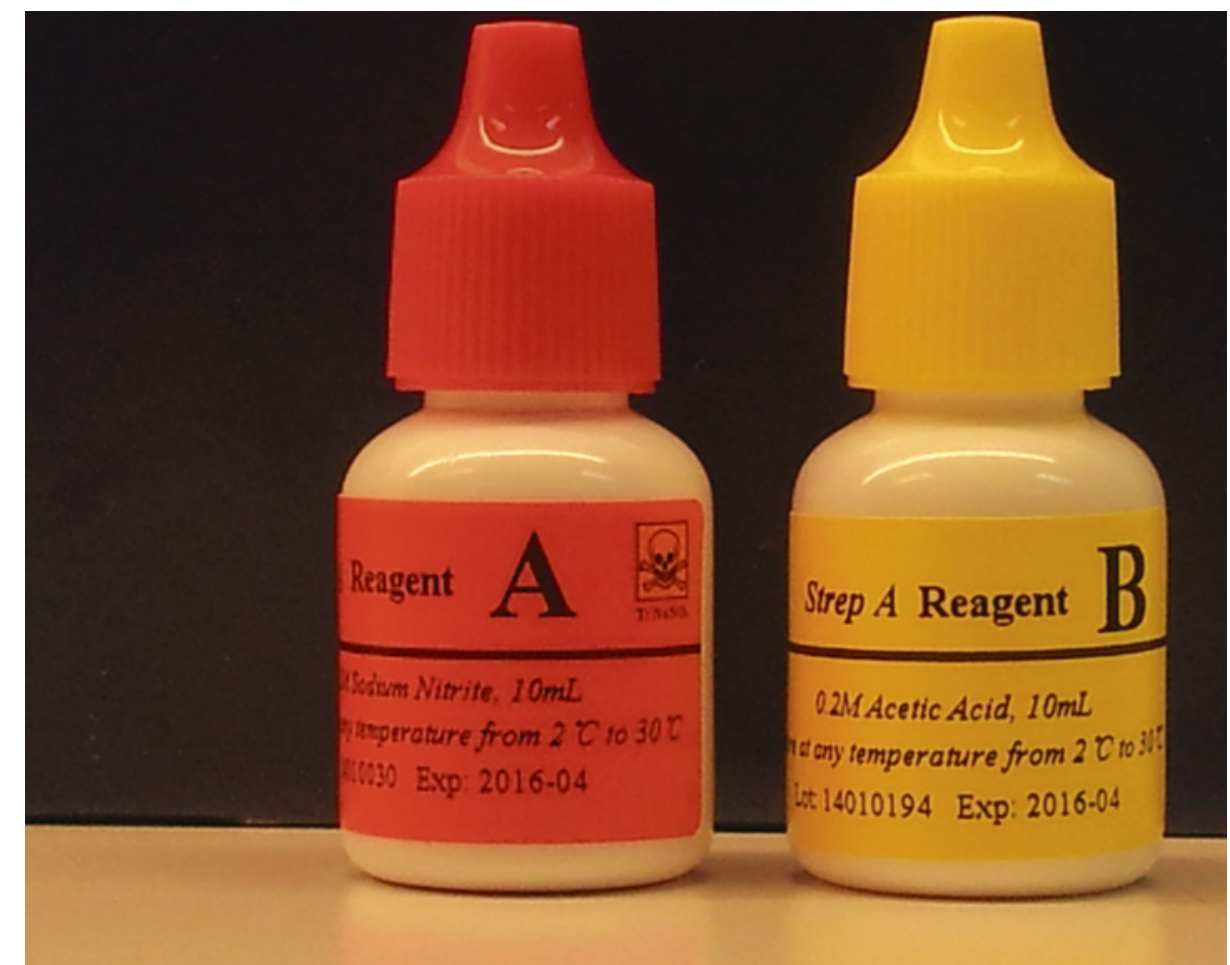

Figur 1 Flasker med streptestreagenser. Flasken til venstre, med giftmerket, inneholder natriumnitritt

ble overvåket, det ble gjort gjentatte blodgassanalyser, og hun fikk oksygentilførsel.

Tre timer etter innleggelse var methemoglobinnivået sunket til $8 \%$, og neste dag var det normalisert. Hun fikk deretter psykiatrisk tilsyn og ble lagt inn i psykiatrisk avdeling.

\section{Diskusjon}

Hemoglobin består av fire polypeptidkjeder med hvert sitt hemmolekyl. Hvert hemmolekyl har et jernatom sentralt som binder oksygen. I normalt hemoglobin antas jern å foreligge $\mathrm{i}$ toverdig form, $\mathrm{Fe}^{2+}$. Methemoglobin er en oksidert form av hemoglobin, der jernet i hemoglobin oksideres fra $\mathrm{Fe}^{2+}$ til $\mathrm{Fe}^{3+}$ (fig 3). Methemoglobin kan ikke transportere oksygen og er mørkebrunt på farge $(1,2)$.

Methemoglobinemi medfører at erytrocyttenes evne til å frakte oksygen er nedsatt, noe som gir vevshypoksi og cyanose som ikke bedres av oksygenbehandling. Normalt nivå av methemoglobin i humant blod er under $1 \%$, og klinisk redusert oksygentransport inntreffer ved nivåer på $10 \%$ eller mer. Symptomer på methemoglobinemi er cyanose, søvnighet, sløvhet, slapphet, ataksi, dyspné, takykardi, kvalme og oppkast. Blodet blir brunblått og gir klinisk såkalt sjokoladecyanose. Urinen kan bli brunsvart, og det vil ofte være proteinuri. Stiger verdiene til mer enn 30-40\%, inntrer mer alvorlige fenomener som sentralnervøs depresjon, bevisstløshet og arytmier. Methemoglobinnivå over om lag $70 \%$ antas å være dødelig $(1,2)$.

Ved methemoglobinemi finner man ofte en diskrepans mellom $\mathrm{pO}_{2}$ og $\mathrm{SaO}_{2}$. Arteriell blodgassanalyse viser tilnærmet normal $\mathrm{pO}_{2}$, mens perifer metningsmåling $\left(\mathrm{SaO}_{2}\right)$ faller. $\mathrm{pO}_{2}$ uttrykker mengden av oksygen løst i plasmadelen av blodet, dvs. partial-

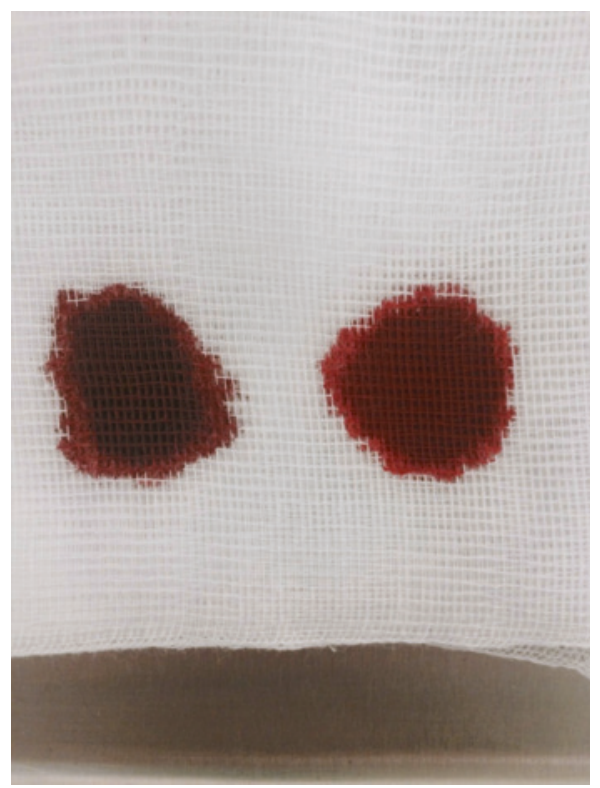

Figur 2 Brunt blod. Pasientens arterieblod til venstre. Behandlende leges arterieblod til høyre 
trykket av oksygen i plasma. $\mathrm{pO}_{2}$ influeres av flere faktorer: oksygeninnholdet $\mathrm{i}$ innåndingsluften, diffusjonen av oksygen fra alveolene til kapillærblodet og grad av shunting, dvs. den andelen av hjertets minuttvolum som ikke oksygeneres ved passasje gjennom lungene. $\mathrm{SaO}_{2}$, oksygenmetning, oppgis som prosent og er et uttrykk for hvor stor andel av hemoglobinet, tilgjengelig for oksygentransport, som faktisk binder oksygen. Målingen av $\mathrm{SaO}_{2}$ med pulsoksymeter er spektrofotometrisk og baserer seg på forholdet mellom oksyhemoglobin og deoksyhemoglobin i blodet. Det varierer mellom ulike modeller pulsoksymetre i hvilken grad methemoglobin innvirker på denne målingen, men generelt faller $\mathrm{SaO}_{2}$ når methemoglobinnivået stiger $(2,3)$.

Methemoglobinemi kan være medfødt, som følge av enzymdefekter, eller skyldes inntak av toksiske agenser, som nitrater, nitritter, metanol, anilin, dapson og enkelte lokalanestetika $(1,2)$.

Nitritter har sterkt oksiderende virkning og er blant de hyppigste årsakene til at det dannes methemoglobin. Eksponering for nitritt skjer hovedsakelig via endogen omdanning fra nitrat. Nitrat er i seg selv relativt ikke-toksisk, men det har vært knyttet bekymring til nitratmetabolittene nitritt, nitrogenmonoksid (NO) og N-nitroso-forbindelser. Human eksponering for nitrat skyldes hovedsakelig inntak via grønnsaker eller forurenset brønnvann, og kroppen har også en viss egenproduksjon (2). De få humane studiene av nitrateksponering som finnes, har ikke vist methemoglobinemi ved inntak av nitrat alene (4). Det anses som usannsynlig at nitratkonsentrasjoner som normalt finnes i føde og vann, forårsaker methemoglobinemi $(5,6)$.

Ulike, flyktige nitritter brukes som rusmidler og afrodisiaka, gjerne under betegnelsen poppers. Det har vært rapportert flere tilfeller av alvorlig methemoglobinemi etter inntak av flyktige nitritter (7).

De fleste methemoglobinemier er milde og krever ingen spesifikk behandling så snart det utløsende agenset er fjernet. Det anbefales å gi oksygen, selv om erytrocyttene har nedsatt evne til å nyttiggjøre seg dette. Metylenblått brukes som antidot og anbefales gitt ved methemoglobinverdier over $25-30 \%$ eller ved alvorlige symptomer. Den anbefalte dosen er $1-2 \mathrm{mg} / \mathrm{kg}$ (1, 2). Metylenblått har raskt innsettende effekt, men kort halveringstid, og det kan være nødvendig med gjentatt dosering. Metylenblått virker ved å inngå som en kofaktor som øker reaksjonshastigheten i enzymsystemer som sørger for å redusere methemoglobinet som er dannet $i$ cellene $(1,2)$. Hos vår pasient ble det maksimalt påvist $22 \%$ methemoglobin. Hun kom seg fint uten annen behandling enn oksygentilførsel.
Tabell 1 Oversikt over pasientens blodgassverdier etter inntak av streptestreagenser

\begin{tabular}{lccccc}
\hline & Referanseverdier & 1 time & 2 timer & 5 timer & 8 timer \\
$\mathrm{O}_{2}$-tilførsel (l) & & Ukjent & 4 & 15 & Ukjent \\
$\mathrm{pH}$ & $7,35-7,45$ & Ukjent & Ukjent & 7,46 & 7,40 \\
$\mathrm{SpO}_{2}(\%)$ & $94-99$ & 82 & $79-83$ & 99 & 99 \\
$\mathrm{PO}_{2}(\mathrm{kPa})$ & $10-14$ & 11,1 & 22,4 & 63,8 & 29,8 \\
$\mathrm{PCO}_{2}(\mathrm{kPa})$ & $4,7-6,0$ & 4,6 & 5,4 & 5,0 & 5,9 \\
Bikarbonat (mmol/l) & $22-26$ & 25,0 & 27,5 & 26,2 & 26,6 \\
Laktat (mmol/l) & $0,5-1,4$ & Ukjent & 0,8 & 1,1 & 0,7 \\
Baseoverskudd (mmol/l) & $-3-3$ & Ukjent & Ukjent & 2,4 & 1,7 \\
Methemoglobin (\%) & $<1,0$ & Ukjent & 22 & 17 & 8 \\
\hline
\end{tabular}

${ }^{1}$ Referanseverdier i henhold til Blåboka, www.uus.no/labus/ (26.10. 2015).
Reagenset i streptestsettet inneholdt natriumnitritt. Det står opplyst på etiketten at reagenset er giftig ved svelging, sterkt etsende og skal oppbevares innelåst og utilgjengelig for barn. Denne kasuistikken viser at streptestreagenset inneholdt natriumnitritt i en mengde stor nok til å forårsake en signifikant methemoglobinemi. Legevakten har i etterkant av denne hendelsen gjennomgått sine rutiner for oppbevaring av streptestsett.

Mottakende lege på lokalsykehuset hadde ikke opplysninger om hva slags agens pasienten hadde inntatt på legevakten da hun ble tatt imot i akuttmottaket. Ambulansepersonellet fikk med seg et innleggelsesskriv fra legevakten, men skrivet kom bort under overføring av pasienten, uvisst hvordan. Ambulansepersonellet ga muntlig rapport om at pasienten hadde inntatt et reagens på legevakten som medførte at pasienten burde observeres på sykehus. Medisinsk bakvakt var informert av legevaktlegen om forgiftningsagenset, men denne opplysningen nådde ikke frem til mottakende lege umiddelbart på grunn av travelt akuttmottak. Ettersom pasienten var stabil ble legevakten a.

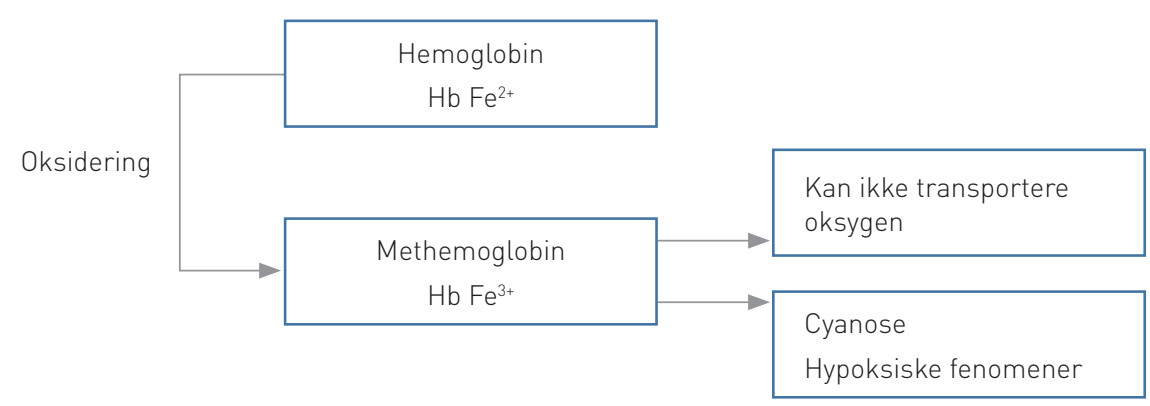

b.

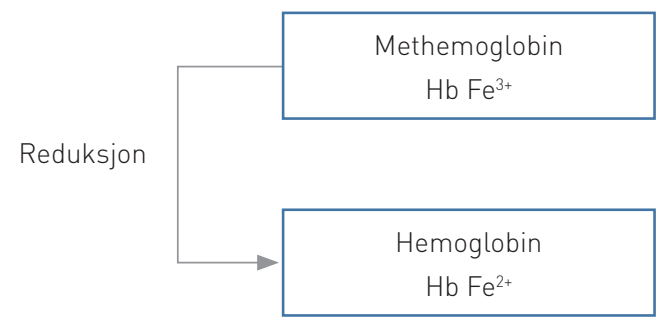

Figur 3 a. I normalt hemoglobin antas jern å foreligge i toverdig form ( $\left.\mathrm{Fe}^{2+}\right)$. Den oksiderte formen for hemoglobin kalles methemoglobin og er verken i stand til å transportere $\mathrm{O}_{2}$ eller $\mathrm{CO}_{2}$. Nitritter har sterkt oksiderende virkning og er en av de hyppigste årsakene til methemoglobinemi (1, 2). b. Enzymsystemer i cellene sørger for å redusere methemoglobin så snart det dannes. Metylenblått kan virke som kofaktor (1, 2) 
kontaktet for å få innleggelsesskrivet overført på nytt, og det ble etter hvert mottatt på faks. Det er alltid en risiko for at viktig informasjon kan forsvinne eller forvrenges når den går gjennom mange ledd, og vår kasuistikk er et eksempel på dette. Det fikk ikke noen konsekvens for pasienten, men kunne vært farlig om forgiftningen hadde vært mer alvorlig.

Pasienten har gitt samtykke til at artikkelen blir publisert.

\section{Vivian M. Dalaker (f. 1979)}

er lege.

Forfatter har fylt ut ICMJE-skjemaet og oppgir ingen interessekonflikter.

\section{Odd Martin Vallersnes (f. 1969)}

er spesialist i allmennmedisin, legeskiftleder og ph.d.-stipendiat.

Forfatter har fylt ut ICMJE-skjemaet og oppgir ingen interessekonflikter.

\section{Linn Elisabeth Fosshaug (f. 1981)}

er lege i spesialisering og stipendiat.

Forfatter har fylt ut ICMJE-skjemaet og oppgir ingen interessekonflikter.

\section{Kirsti S. Andersson (f. 1966)}

er spesialist $\mathrm{i}$ indremedisin og i nefrologi og overlege og seksjonsleder for leger i spesialisering $\mathrm{i}$ indremedisin.

Forfatter har fylt ut ICMJE-skjemaet og oppgir ingen interessekonflikter.

\section{Knut Erik Hovda (f. 1971)}

er spesialist i indremedisin, med doktorgrad i klinisk toksikologi, og overlege. I tillegg jobber han som klinisk bakvakt ved Giftinformasjonen, Folkehelseinstituttet.

Forfatter har fylt ut ICMJE-skjemaet og oppgir ingen interessekonflikter.

\section{Litteratur}

1. Solheim L, Brun A-C, Greibrokk TS et al. Methemoglobinemi - årsaker, diagnostikk og behandling. Tidsskr Nor Lægeforen 2000; 120: 1549-51.
2. Price D. Methemoglobin inducers. I: Flomenbaum NE, Goldfrank LR, Hoffman RS, Howland MA Lewin NA, Nelson LS, red. Goldfrank's toxicologic emergencies. 8. utg. New York: McGraw Hill, 2006 : $1734-45$

3. Reynolds KJ, Palayiwa E, Moyle JT et al. The effect of dyshemoglobins on pulse oximetry: Part I, Theoretical approach and Part II, Experimental results using an in vitro test system. J Clin Monit 1993; 9 $81-90$.

4. Hord NG, Tang Y, Bryan NS. Food sources of nitrates and nitrites: the physiologic context for potential health benefits. Am J Clin Nutr 2009; 90: $1-10$

5. Katan MB. Nitrate in foods: harmful or healthy? Am J Clin Nutr 2009; 90: 11-2.

6. Fewtrell L. Drinking-water nitrate, methemoglobinemia, and global burden of disease: a discussion. Environ Health Perspect 2004; 112: 1371-4.

7. Hunter L, Gordge L, Dargan PI et al. Methaemoglobinaemia associated with the use of cocaine and volatile nitrites as recreational drugs: a review. Br J Clin Pharmacol 2011; 72: 18-26.

Mottatt 12.2. 2015, første revisjon innsendt 29.6. 2015, godkjent 26.9. 2015. Redaktør: Lise Mørkved Helsingen. 